\title{
PRACTICE SCHEDULES AND HIERARCHICAL ORGANIZATION IN THE ADAPTIVE PROCESS OF MOTOR LEARNING
}

\author{
Thiago de Oliveira Souza; Umberto Cesar Corrêa
}

School of Physical Education and Sport. University of São Paulo, Brazil.

\begin{abstract}
The aim of this study was to investigate the effects of different practice schedules on the hierarchical organization of motor skills in the adaptive process. Forty volunteers, both men and women, with an average age of 28.7 years $(S D \pm 8.1$ ) took part in the experiment. The design consisted of two phases (stabilization and adaptation) and four practice groups: constant; constant-random; random; and random-constant. Participants performed 90 trials of golf putting strokes in the stabilization phase and 30 trials in the adaptation phase. Hierarchical or ganization was accessed by measures of macrostructure (relative displacement and timing) and microstructure (total displacement and time). Cluster analyses were run to infer the emergence of movement patterns over practice. Results showed that constant, random and random-constant groups altered macro and microstructure and improved performance in the stabilization phase. However, their performance worsened after perturbation. It was also verified that consistency of the macrostructure was lower than that of the microstructure. It was concluded that constant, random and random-constant practices made possible the partial formation of the macro and microstructures, since they did not become functional.
\end{abstract}

Keywords: motor learning, variability, adaptive system, golf putting

\section{PROGRAMAS DE PRÁCTICA Y ORGANIZACIÓN JERÁRQUICA EN EL PROCESO ADAPTATIVO DEL APRENDIZAJE MOTOR}

\begin{abstract}
RESUMEN
El objetivo de este estudio fue investigar los efectos de diferentes programas de práctica en la organización jerárquica de las habilidades motoras en el proceso adaptativo. Cuarenta voluntarios, tanto hombres como mujeres, con una edad promedio de 28.7 años (DE \pm 8.1) participaron en el experimento. El diseño constó de dos fases (estabilización y adaptación) y cuatro grupos de práctica: constante; constante-aleatorio; aleatorio; y aleatorio constante. Los participantes realizaron 90 pruebas de golpes de golf en la fase de estabilización y 30 pruebas en la fase de adaptación. La organización jerárquica se abordó mediante medidas de macroestructura (desplazamiento relativo y sincronización) y microestructura (desplazamiento total y tiempo). Se realizaron análisis de "clúster" para inferir la aparición de patrones de movimiento sobre la práctica. Los resultados mostraron que los grupos constantes, aleatorios y constantes aleatorios alteraron la macro y la microestructura mejorando el rendimiento en la fase de estabilización. Sin embargo, su rendimiento empeoró después de la perturbación. También se verificó que la consistencia de la macroestructura era menor que la de la microestructura. Se concluyó que las prácticas constantes, aleatorias y aleatorias constantes hicieron posible la formación parcial de las macro y microestructuras, ya que no se volvieron funcionales.
\end{abstract}

Palabras clave: aprendizaje motor, variabilidad, sistema adaptativo, golf putting

\footnotetext{
Correspondence:

Umberto Cesar Corrêa

School of Physical Education and Sports. University of São Paulo, Brazil.

umbertoc@usp.br
}

Submitted: 24/01/2020

Accepted: 05/06/2020 


\section{INTRODUCTION}

In the last few years, the adaptive process of motor learning has emerged as an alternative model for explaining and understanding how people acquire motor skills (e.g. see Tani et al., 2014). One could say that the main differential of this model is that it explains acquisition not only as a process of functional pattern formation, but also as a process of pattern transformation (Barros, Tani, \& Corrêa, 2017; Corrêa, Correia, \& Tani, 2016; De Paula Pinheiro, Marques, Tani, \& Corrêa, 2015).

As an adaptive process, motor learning unfolds as a process in which the stabilization and adaptation are repeated as learning phases in order to characterize it as continuous (Choshi, 1985; Choshi \& Tani, 1983). 'Stabilization phase' refers to the process of functional patterning in which negative feedback mechanisms work to reduce the discrepancies between the desirable state and the current state of a system (learner). Such mechanisms also function as regulatory processes for maintaining steady state, i.e. stable pattern (Ford \& Lerner, 1992).

Similarly to the acquisition phases in traditional and contemporary motor learning models (e.g. Closed-Loop, Scheme, Direct-Learning and Skilled Optimization of Control), in early stabilization, interaction between the components of a motor skill is weak or nonexistent and its spatiotemporal organization is poorly defined, with many degrees of freedom and high variability. With practice, interaction between components becomes standardized, degrees of freedom are reduced and a pattern configuration is established, which makes it possible to achieve function (Tani et al., 2014).

An important question here is: what happens after stabilization has been achieved? To explain the continuing nature of motor learning, a second phase is proposed based on the conception of motor skills as open systems. This is a type of system capable of changing its internal organization to evolve due to its interaction (energy and information exchange) with its environmental context (von Bertalanffy, 1952). Motor skills only exist in context. They are adaptive phenomena in nature since human beings have performed them as a means to interact with their environment in order to fulfil their needs (e.g. health, education and leisure) and, therefore, survive. Because human beings-environment interactions are dynamic, motor skills are subject to different types and levels of perturbation, to which they have to adapt in order to reach their purposeful (Salthe, 2012).

A perturbation can be anything that causes change or uncertainty for the individual (De Paula Pinheiro et al., 2015). Achieving stabilization is an important aspect for any system, as it is a prerequisite for dealing with perturbation, whether environmental or system-wide (Kelso \& Engstrøm, 2006). A system can deal with a perturbation in such a way that its interacting 
components preserve the integral configuration of the behaviour structure and tend to restore it (Weiss, 1971). Such perturbations are related to situations in which one component deviates greatly from the direction of the pattern, but the others automatically change course to neutralize the perturbation and return to its configuration (Salthe, 2012). This could be thought of as a type of parameterization process, i.e. alteration of a specific value of time, space or force (Schmidt, 1982).

However, there may be perturbations that go beyond the limit of acquired stability being supported, which would make the system unstable and a new pattern would be required. In terms of motor learning, this implies the adaptation phase (Tani et al., 2014). For instance, during performance of a soccer penalty shooting, the goalkeeper's posture may require that a shot be performed faster, that is, through only altering the shooting velocity parameter. However, the goalkeeper could move, causing such a perturbation that the shooter has to change the shooting structure by altering the support position from the left to the right foot (structural reorganization). Still, he/she could also perform a completely new penalty shooting by performing a turn on his/her longitudinal axis so that he/she has his/her back to the goalkeeper and kick the ball with the back heel, similarly to player Awana in the United Arab Emirates vs. Lebanon in 2011. In sum, structural adaptation implies a system achieves new state of organization as a basic nature of complex adaptive systems seeking growing complexity (Holland, 1995; Kauffman, 1995; Lewin, 1999).

At this point the main question is: in terms of motor learning how or what would enable these kinds of adaptation to take place? To put it in another way: how has the adaptive process been explained? It has been proposed that the process of functional stabilization implies the formation of an underlying motor control structure capable of simultaneously addressing the fundamental contradictory features of motor skills: consistency and flexibility (Corrêa et al., 2015). This is made possible by conceiving motor skills and their underlying control structure as a system organized hierarchically. This refers to a kind of multilevelled system that presents consistency and regularity at the macroscopic level and variability in at microscopic one (Weiss, 1971). In terms of motor skills, these levels have been named 'macrostructure' and 'microstructure', respectively.

The macrostructure emerges from the interaction between the system's components. It is constrained by the motor skill context and goal. Because of this, macrostructure reflects the motor skill's overall configuration, i.e. overall pattern. In turn, microstructure refers to the individual components and, therefore, is more variable than macrostructure (Corrêa et al., 2015). For instance, the aforementioned soccer penalty shooting is composed of the interaction of approaching the ball, supporting a position with the non-kicking 
foot, looking at the ball and holding the head steady, contacting the ball and transferring weight forwards. Whereas this sequential interaction is 'invariable', the way the player approaches the ball, how he/she position the support foot, which part of the foot touches the ball and how fast vary according to the soccer penalty contexts. Importantly, in complex adaptive systems, the hierarchy consists of the macrostructure to constrain the mode of interaction of components rather than to control them individually (Laszlo, 2002). In short, one of the advantages of assuming this conception of hierarchical organization is that it can identify different ways that a system can deal with perturbations, that is, adaptation. On the one hand, the fact that the macrostructure is characterized by consistency and regularity rather than stiffness allows its reorganization. On the other, the parameterization details characterize the microstructure as an emergent phenomenon.

Recently, such a view of hierarchically organized systems has been utilized as an explanatory hypothesis for beneficial effects of a practice schedule on the learning motor skills. Specifically, studies have shown that a constant-random schedule promotes a better capacity of adaptation compared to a constant, random and random-constant one (Barros et al., 2017; Corrêa, Benda, Meira Jr., \& Tani, 2003; Corrêa, Ugrinowitsch, Benda, \& Tani, 2010), and such capability is acquired by an optimum amount of these sequential schedules (Corrêa, Massigli, Barros, Gonçalves, Oliveira, \& Tani, 2010; Corrêa, Walter, TorrianiPasin, Barros, \& Tani, 2014; De Paula Pinheiro et al., 2015). The main explanation for these results is that constant practice facilitates the forming of a pattern of interaction between skill components (macrostructure) and subsequent random practice allows its diversification by variability in the microstructure (De Paula Pinheiro et al., 2015).

Despite the explanatory potential of this conception of a hierarchical organized system, not much attention has been given in experimental terms to how the practice schedule would affect the hierarchical organization of motor skills in the adaptive process of motor learning. Therefore, the aim of this study was to investigate the effects of different practice schedules on the hierarchical organization of motor skills in the adaptive process. We hypothesized that a constant-random schedule would allow the formation of a structure with macro consistency and micro variability, i.e. that the macrostructure variability would be significantly lower than the microstructure variability. This is because constant practice would first enable consistency to the macrostructure and, posterior random practice, the diversification observed in the variability of the microstructure. In contrast, it was expected that: (i) only constant practice would imply consistent macro- and microstructures; (ii) only random practice would imply inconsistency in the macrostructure; (iii) and, foreground random practice would make it difficult to form the macrostructure and, when constant 
practice is introduced, emphasis would be given only to consistency. In short, it was expected that there would hardly be differentiation between the macro and microstructural variabilities of the patterns formed by these practice regimes.

\section{METHOD}

\section{Participants}

Forty volunteers, both men and women, with an average age of 28.7 years $(\mathrm{SD}=8.1$ ) took part in the experiment. They were all those younger adults, healthy, residents of a condominium in the Greater São Paulo, Brazil, who had no experience with the sport of golf. Participation required the volunteers' written consent. The experimental protocol was approved by the local Institutional Review Board.

\section{Equipment and task}

The learning task was golf putting. This task was used because it allowed clear identification and measurement of its components - i.e. micro- and macrostructure - and the ways they interact. There are two movement phases: (1) backswing (from the beginning of the movement near the ball up to the highest point reached by the club); (b) forward swing (from the end point of the backswing to the end of the movement after the impact on the ball) (Figure 1A). Furthermore, existing research provides experimental protocol for motor learning (e.g. Chauvel et al., 2012; Nunes et al., 2018; Oliveira, Denardi, Tani, \& Corrêa, 2013; Poolton, Maxwell, Masters, \& Raab, 2006).

As in Nunes et al. (2018)'s study, participants performed the strokes on an artificial grass surface measuring $1.5 \mathrm{~m}$ wide and $5 \mathrm{~m}$ long, with a target (hole with a diameter of $10.0 \mathrm{~cm}$ ) $15 \mathrm{~cm}$ from the end of the surface. We used two golf clubs (male and a female putters designed for beginners) and 15 championship golf standard balls (Figure 1B). A tablet computer for data tabulation and a video camera (Sony HDR CX240) positioned in front of the station at a distance of $3.0 \mathrm{~m}$ was used to record all trials. 


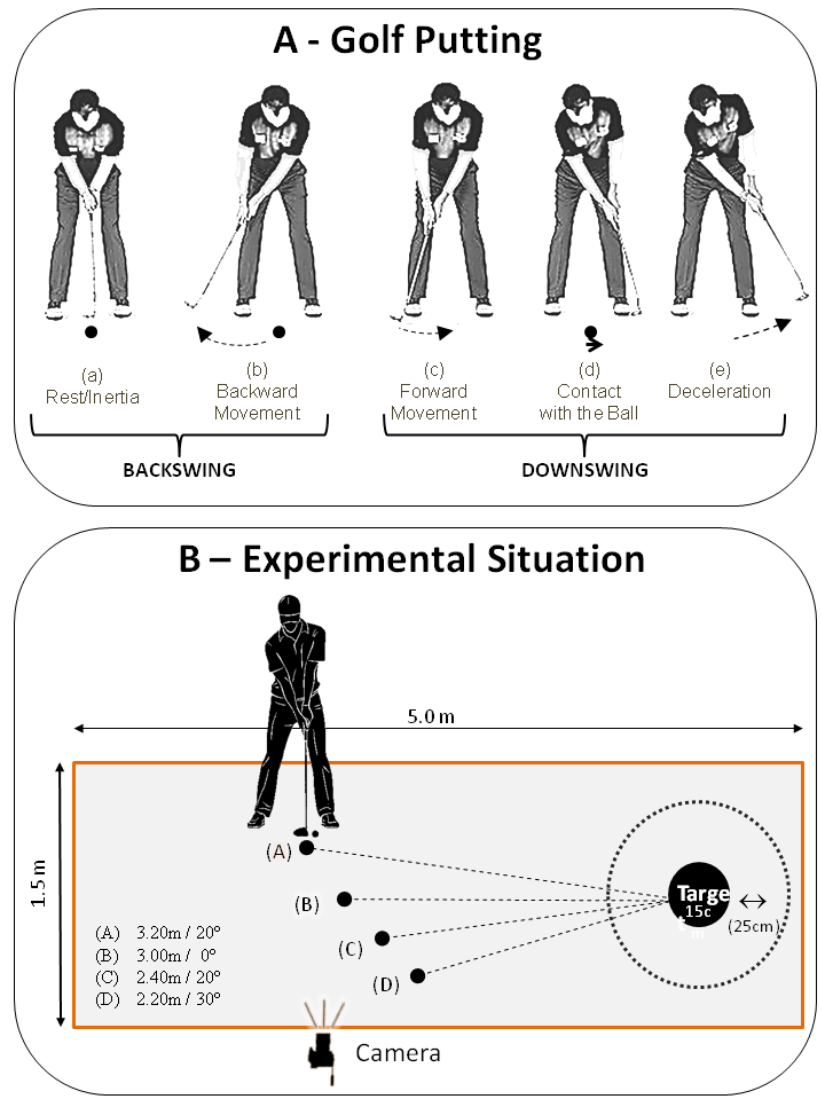

FIGURE 1: Illustration of (A) golf putting components (backswing and downswing), and (B) experimental situation.

For data collection, markers were added to the club head to aid with tracking the movement of the club, and the participants were filmed at a $30 \mathrm{~Hz}$ acquisition rate, with a resolution of $640 \times 480$. For video analysis, we used the Skillspector software (version 13.1). Data extracted from the software were the time and displacement trajectories of the club based on $x$ and $z$ axis.

\section{Design and procedures}

Participants were randomly distributed by considering a counterbalancing of sex into four groups of a practice schedule $(n=10)$ : constant, constantrandom, random and random-constant. The experimental phases were stabilization and adaptation, in which the participants performed 90 and 30 trials, respectively.

In the stabilization phase, the constant group performed all trials at a distance of $3 \mathrm{~m}$ from the target (hole) and direction $0^{\circ}$ (position B, Figure 1). The random group performed the 90 trials varying randomly the direction and 
distance from the target (position $\mathrm{A}=3 \mathrm{~m}$ and $0^{\circ}$; position $\mathrm{C}=2.4 \mathrm{~m}$ and $20^{\circ}$ left; position $\mathrm{D}=2.2 \mathrm{~m}$ and $30^{\circ} \mathrm{left}$ ). The constant-random group performed the first half of the trials similarly to the constant group and the first half varying randomly the distance the direction from the centre of the hole, similar to the random group. Finally, the random-constant group performed the first 45 trials varying randomly the distance the direction from the centre of the hole, and the remaining trials at a distance of $3 \mathrm{~m}$ from the target (hole) and a direction $0^{\circ}$. The adaptation phase was similar for all groups, being two blocks of 15 trials in which the task modification consisted of performing a stroke from another place (new direction and distance (position A, Figure 1B).

Data collection was carried out in a closed room, one participant at a time. After receiving general information about the experiment, the participant was asked about his/her interest in participating. He/she was placed on the artificial grass surface and instructed about how to handle the club and to perform the shot with a single motion, that is, moving the club without any preparatory movement. In addition to verbal instruction, the participant also watched a video of an expert performing the task. After verifying that no doubts remained, the participant was asked to perform three shoots at 1 metre from the target in order to demonstrate understanding. Finally, the participant was informed he/she could leave the experiment at any time, if he/she wanted. The participant could perform a trial at any time after the replacement of the ball. Data collection lasted about 40 minutes.

\section{Data analyses}

The dependent variables included measures related to movement pattern (macro- and microstructures) and task goal (accuracy and consistency of performance).

Movement pattern. Macro- and microstructure of movement pattern were calculated by considering the two aforementioned components: (C1) backswing (from the beginning of the movement near the ball up to the highest point reached by the club); (C2) forward swing (from the end point of the backswing to the end of the movement after the impact on the ball). Microstructure was accessed through measures of overall time (seconds) and displacement amplitude (centimetres) by considering the initio of $\mathrm{C} 1$ and final of $\mathrm{C} 2$, which resulted in Mit and Mid, where Mi referred to microstructure, $t$ was the time (seconds) and $d$ referred to the displacement (centimetres).

In turn, macrostructure was accessed by relative timing and relative displacement of each component as a proportion of each one relative to the overall pattern, as follow: 


$$
\begin{aligned}
& M a t C 1=\frac{t C 1}{(t C 1+t C 2)} \times 100 \text { and MatC2 }=\frac{t C 1}{(t C 1+t C 2)} \times 100 \\
& M a d C 1=\frac{d C 1}{(d C 1+d C 2)} \times 100 \text { and MadC2 }=\frac{d C 2}{(d C 1+d C 2)} \times 100,
\end{aligned}
$$

were $M a$ referred to macrostructure, $\mathrm{C}$ was the component, $t$ referred to time (seconds) and $d$ was the displacement (centimetres).

By considering that in a hierarchical system the variance of the whole (macrostructure) is predicted to be significantly smaller than the variance of the parts (microstructure) (Weiss, 1967, 1969, 1971), from the relative timing and relative displacement the consistency of the macrostructure was calculated through $C V=\sigma / \mu$, where $C V$ was the ratio of variability, $\sigma$ was the standard deviation of relative time/displacement, and $\sigma$ was the arithmetic mean relative time/displacement in blocks of 10 trials. Similar procedures were run for variability of the microstructure.

From the variability of macro- and microstructure components, each of them was plotted into its respective block of trial (MatC1, MatC2, MadC1, MadC2; Mit, Mid) in order to characterize the task as a whole, i.e. macro-and microscopic patterns. From plotted data over blocks, we ran a cluster analysis using Ward's minimum variance method with Euclidean distance (Johnson \& Wichern, 2001). The output of this analysis is a tree diagram (dendrogram), which shows the distance (similarity level) on the $y$ axis, and the cluster items (blocks of trials) are represented on the $x$ axis. After the cluster analysis algorithm was run, a cut-off level of $25 \%$ of the total height of the dendrogram was assigned based on the distinctness, compactness and weight of the clusters (Everitt, Landau, \& Leese, 2001; Kaufman \& Rousseeuw, 1990). Since the blocks of trials were sequential, these analyses made it possible to infer whether a group performed the same or different patterns over the stabilization and adaptation phases. To put it in another way, it was possible to verify how the macro and microstructure behave in the stabilization phase and how adaptation took place in relation to this. For this purpose the following blocks of 10 trials were considered: first (S1), two intermediates (S4 and S5) and last (S9) stabilization blocks, and all blocks of the adaptation phase (A1, A2 and A3).

Task goal. Performance related to the task goal was analysed in terms of accuracy and consistency being the basic characteristics of motor skills. Here, the dependent variable was the scores derived from hitting the target. A circle was formed at a $25 \mathrm{~cm}$ radius from the hole, which allowed the following scores: 10 when hitting the ball into the target (hole); 5 when the ball stopped at a distance less than $25 \mathrm{~cm}$ from the centre of the hole. When the ball stopped at a distance greater than $25 \mathrm{~cm}$ from the centre of the hole, it was assigned a score of 0 . These measurement procedures resulted from pilot studies developed in 
order to find a suitable and sufficiently sensitive measure to infer the learning phenomenon.

The performance accuracy was calculated by $\mathrm{AI}=\Sigma \mathrm{PS} / \Sigma \mathrm{PP}$, where $\mathrm{AI}$ is the accuracy index, PS referred to points scored, and PP was the possible points that could be achieved. Performance consistency was calculated by $\mathrm{CV}=\sigma / \mu$, where $\mathrm{CV}$ was the ratio of variability, $\sigma$ referred to the standard deviation, and $\mu$ was the arithmetic mean. These calculations involved the same blocks of 10 trials of the previous analyses.

A one-way ANOVA was run for each group to verify the changes in performances in each experimental situation. After that, a mixed-model ANOVA $4 \times 3$ (groups $x$ blocks of trials) was conducted with data from the adaptation phase to compare the groups in this phase. For these analyses, the observed significant effects were further assessed using the Fisher $_{\text {LSD }}$ post hoc test.

Finally, variabilities of the macro- and microstructure were compared in order to verify the formation of [the] hierarchical organization. For this purpose, the foregoing temporal and spatial ratios of variability (CV) were considered for comparisons in the first and last stabilization blocks and the first and last adaptation blocks by a paired Student's t-test.

These analyses were preceded by Shapiro-Wilk's W and Bartlett's tests of normality and homogeneity of variance. The level of significance was set at $p$ $<.05$ using Statistica ${ }^{\circledR} 13.0$ software (Stat Soft Inc., Tulsa, USA).

\section{RESULTS}

Constant group. As Figure 2A shows, the statistical analysis (Ward method with Euclidean distance) revealed four patterns of macrostructure for the constant group, P1, P2, P3 and P4, which were performed in S1, S9, S4-S5 and A1-A2-A3 blocks of trials, respectively. Regarding microstructure, Figure 2B shows five patterns, P1, P2, P3, P4 and P5, which were performed in S1, S9A3, S4-A2, A1 and S5 blocks of trials.

Concerning the task goal measures (Figure 3), a one-way ANOVA revealed effects only for accuracy of performance, $\left[F(6,54)=2.93, p<.05, \eta p^{2}\right.$ $=.24]$. The Fisher ${ }_{\text {LSD }}$ test showed that the constant group increased accuracy from the first to the fourth stabilization block, and decreased it from this block to the adaptation blocks $(p<.05)$.

These results mean that in the stabilization phase, the macrostructure was changed from S1 to S4, maintained itself to S5 and was altered to S9; the microstructure changed block by block; and performance accuracy improved only from the first to the fourth block. When the task was changed a new macrostructure was observed in all adaptation blocks. The same occurred with the microstructure, but only in the first block (A1). Changes in the macro- and microstructure to S4 were accompanied by an improvement in performance 
accuracy. However, the new structures in the adaptation phase implied a drop in performance to the level of the previous phase.

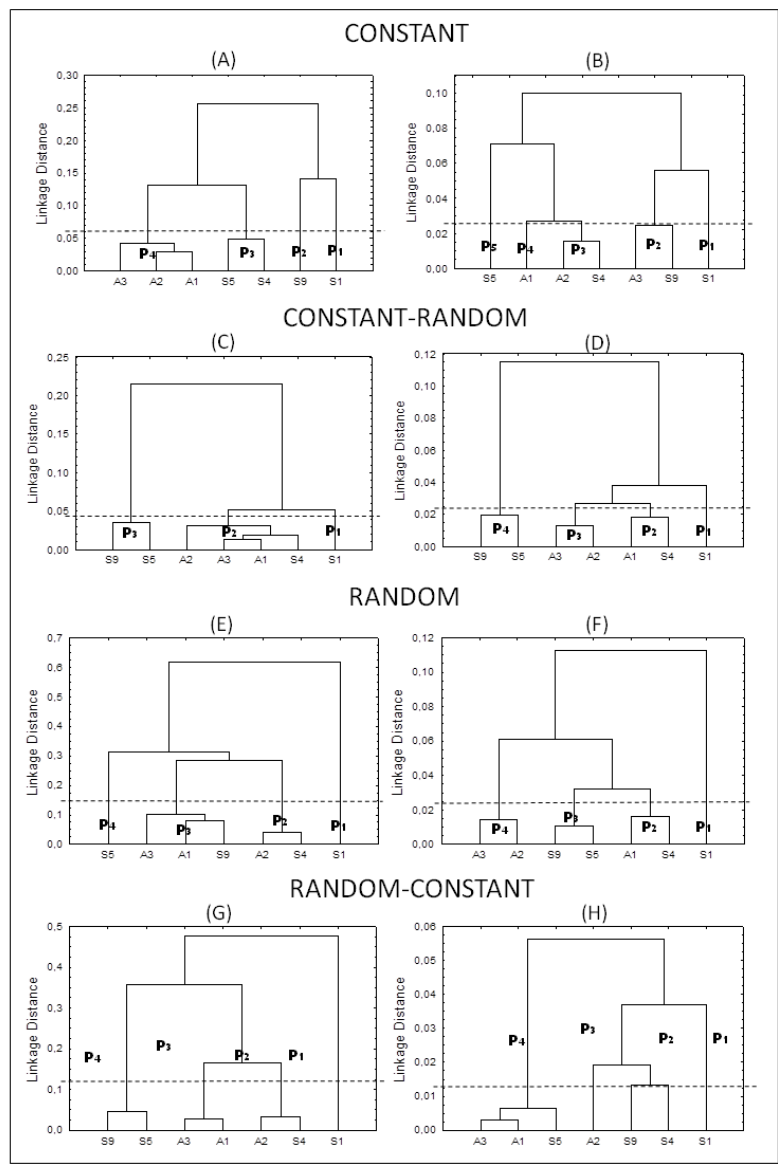

FIGURE 2: Patterns (P) of macrostructures [constant (A), constant-random (C), random (E) and random-constant $(\mathrm{G})$ ] and microstructures [constant (B), constant-random (D), random $(\mathrm{F})$ and random-constant $(\mathrm{H})]$ of experimental groups in the trial blocks of stabilization (S1, S4, S5 and S9) and adaptation (A1, A2, and A3) phases.

Constant-random group. As Figure 2C shows, the statistical analysis (Ward method with Euclidean distance) revealed three patterns of macrostructure for the constant-random group, P1, P2 and P3, which were performed in S1, S4-A1-A2-A3 and S5-S9 blocks of trials, respectively. Regarding the microstructure, Figure 2D shows four patterns, P1, P2, P3 and P4, which were performed in S1, S4-A1, A2-A3 and S5-S9.

Concerning the task goal measures (Figure 3), similarly to the previous results a one-way ANOVA revealed effects only for accuracy $[F(6,54)=3.15, p<.05$, $\left.\eta p^{2}=.25\right]$. The Fisher ${ }_{\text {LSD }}$ test showed that the constant-random group 
decreased accuracy from the last stabilization block to the first and second adaptation blocks $(p<.05)$.

These results allow the inference to be made that macrostructure changed from S1 to S5, and a new pattern was performed in the adaptive phase. Similar behaviour occurred with the microstructure, although it also changed during adaptation. However, these changes did not imply improvement in performance. Actually, they were accompanied by a decrease in performance in the adaptation phase.

(A)

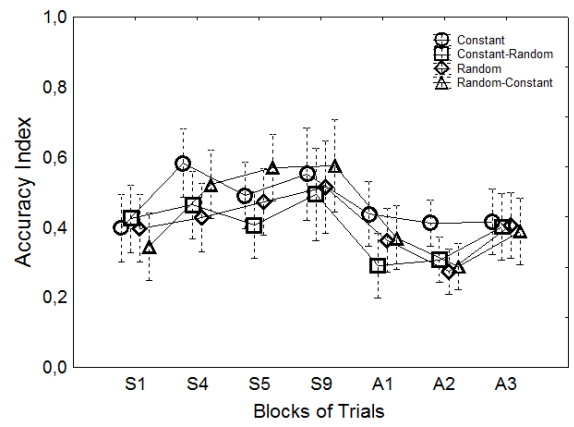

(B)

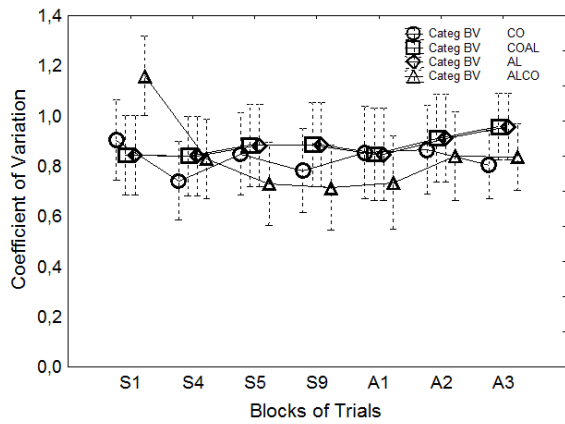

FiguRE 3: Accuracy (A) and variability (B) indexes of the constant, random, constantrandom, and random-constant groups.

Random group. As Figure 2E shows, the statistical analysis (Ward method with Euclidean distance) revealed four patterns of macrostructure, P1, P2, P3 and P4, which were performed in S1, S4-A2, S9-A1-A3 and S5 blocks of trials, respectively. For the microstructure, Figure $2 \mathrm{~F}$ also shows four patterns, P1, P2, P3 and P4, which were performed in S1, S4-A2, S9-A1-A3 and S5.

Regarding the task goal measures, a one-way ANOVA revealed effects only for performance accuracy $\left[F(6,54)=3.14, p<.05, \eta p^{2}=.25\right]$. The Fisher $_{\text {LSD }}$ test showed that the random group increased accuracy from the first to the last block and decreased it from this block to the first adaptation block $(p<.05)$.

These results indicate that the macro- and microstructure were changed over stabilization and adaptation. It is interesting to note that these changes implied an improvement in performance over stabilization. However, when the task was changed, both structures were modified and performance deteriorated.

Random-constant group. As Figure 2G shows, the statistical analysis (Ward method with Euclidean distance) revealed four patterns of macrostructure, $\mathrm{P} 1$, P2, P3 and P4, which were performed in S1, S4-A2, A1-A3, and S5-S9 blocks of trials, respectively. Similarly, Figure $2 \mathrm{H}$ shows four patterns of microstructure, 
P1, P2, P3 and P4, which were performed in S1, S4-S9, A2 and S5-A2 blocks, respectively.

Concerning the task goal measures (Figure 3), a one-way ANOVA revealed effects only for performance accuracy $\left[F(6,54)=3.93, p<.01, \eta p^{2}=.30\right]$. The Fisher $_{\text {LSD }}$ test showed that the random-constant group increased accuracy from the first to the last stabilization block and decreased it to the first and second adaptation blocks $(p<.01)$.

These results mean the macro- and microstructure were modified throughout the stabilization phase. Interestingly, these changes were accompanied by improvement in performance accuracy. When the task was changed, the macrostructure was modified and a new pattern was executed in two blocks of trials (A1 and A3). A new standard was observed for the microstructure in A2. However, these changes implied a decrease in performance.

Concerning the adaptation phase, a ANOVA $4 \times 3$ (groups $\times$ blocks of trials) revealed significant effects only for blocks of trials related to performance accuracy $\left[F(2,72)=6.93, p<0.01, \eta p^{2}=0.16\right]$. The Fisher ${ }_{\text {LSD }}$ test showed that the second adaptation block was more accurate than the remaining blocks ( $p$ $<.05$ ).

Finally, regarding comparison between variabilities of the macro- and microstructure in the initial and final of stabilization phase (Figure 4), a paired Student's t-test revealed the following differences for temporal dimension: constant (S1: $t=3.68, p<0.01$; S9: $t=3.84, p<0.01$ ), constant-random (S1: $t=$ 2.69, $p<0.05$ ), random (S1: $t=4.07, p<0.01$; S9: $t=4.07, p<0.01$ ), random-constant (S1: $t=3.22, p<0.05$; S9: $t=2.53, p<0.05)$. With relation to spatial dimension, a paired Student's t-test revealed the following differences: constant (S9: $t=3.02, p<0.05$ ), constant-random (S9: $t=4.40, p<0.01$ ), random (S1: $t=5.59, p<0.01$; S9: $t=6.96, p<0.01$ ), random-constant (S1: $t=$ 5.59, $p<0.01$; S9: $t=6.96, p<0.01$ ). In summary, these results allow us to infer that the variability of the macrostructure in the temporal and spatial dimensions were superior to the variability of the microstructure in all practice groups. 

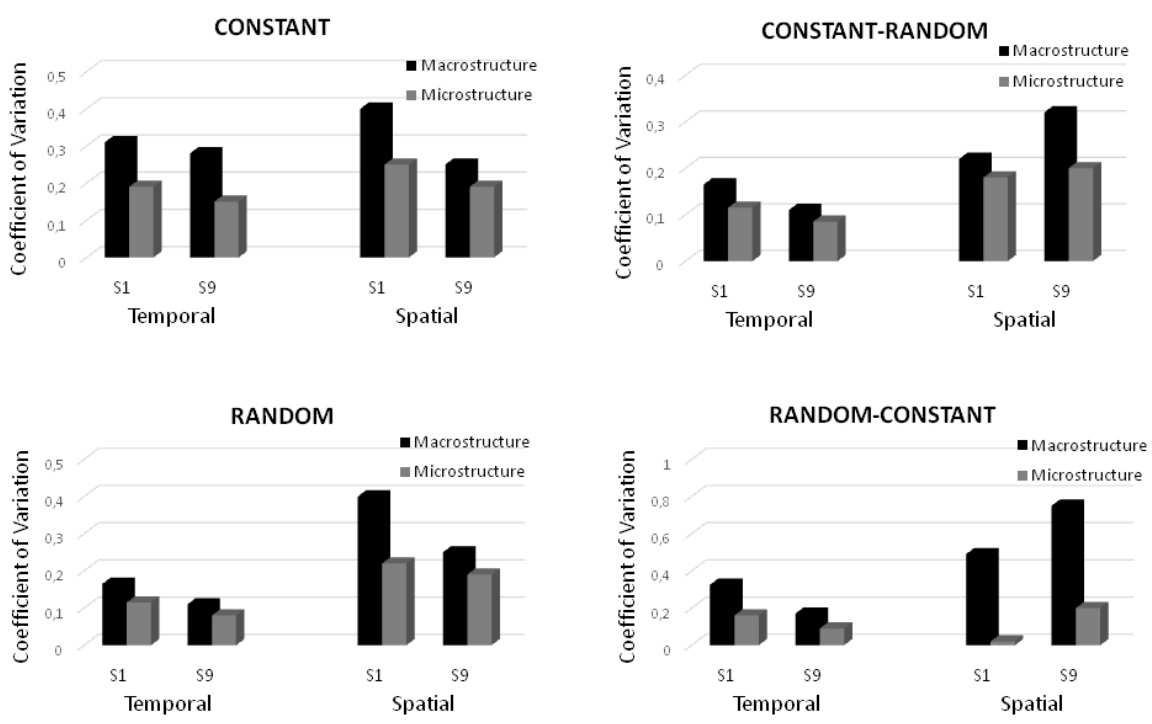

FIGURE 4: Variability of the macro- and microstructures of the constant, random, constant-random, and random-constant groups at the beginning and end of the stabilization phase.

\section{DisCUSSION}

The aim of this study was to investigate the effect of different practice schedules on the hierarchical organization of motor skills in the adaptive process. The hypotheses raised were not supported due to the following results: constant, random and random-constant groups showed changes in the macrostructures and microstructures, which were accompanied by improved performance in the stabilization phase. However, when the task was modified, performance deteriorated. With perturbation, the random group kept the same pattern and then returned to another pattern already performed, but it was not enough to deal with the perturbation, since there was a decrease in performance. The random-constant group, on the other hand, assumed a new pattern with task modification, but it was not enough to support the perturbation for the same reason as the previous group.

The constant practice group also showed changes in macro- and microstructures, but only at the beginning of the stabilization phase. Such changes seemed to have reflected in performance, which improved only early in practice. With the modification of the task, it assumed a new pattern, but similarly to the other groups it did not result in adaptation, as performance dropped. Regarding the constant-random practice group, changes in the macro- and microstructures did not reflect on performance. In addition, when 
there was a change in the task, the performance that had not improved during the stabilization phase showed an even worse performance.

It may be suggested that constant, random, and random-constant were those practice schedules that made possible advances in the stabilization process, but not to the point of achieving functionality. The fact that the statistical analyzes reveal small effect sizes allows us to suggest that the differences between the blocks of trials that indicated the improvement in performance were very small to the point that the system became functional. As the results showed, the blocks that differed significantly from each other also had overlap between the confident intervals. Instead of that, it is possible that groups have only reached the pre-stabilization. In this regard, in order to obtain supporting evidence that functional stabilization is a prerequisite for the adaptive process, studies have used a design in which the stabilization phase is experimentally separated into pre-stabilization, stabilization and superstabilization (e.g. Benda et al., 2010; Benda, Corrêa, Ugrinowitsch, Ambrósio, \& Tani, 2016; Ugrinowisth et al., 2010). Pre-stabilization refers to the level before functional stabilization, in which the component interactions begin to sketch the desired movement pattern, but still do not achieve the desired environmental result; stabilization, as already mentioned, is that state in which a system performs its function, i.e. the desired result is reached with consistency and flexibility; and, super-stabilization refers to that state after function has been achieved in which continuity of practice results in gaining competence at a level that a system shows redundancy or play behaviour. Importantly, this assumption suggests caution in interpreting the performance level achieved in previous studies that investigated golf putting learning (e.g. Chauvel et al., 2012; Nunes et al., 2018; Oliveira, Denardi, Tani, \& Corrêa, 2013), since we based some aspects of our task design on them.

Another aspect that may contribute to the previous interpretations refers to the fact that the macrostructure remained more variable than the microstructure for all groups to the end of the stabilization phase. It has been proposed that at the beginning of the stabilization process the macrostructure does not exist or the interactions between the components are weak to the point of not setting a spatiotemporal pattern (Tani, 1995, 2005). This implies that components have many degrees of freedom and high variability. At this time, the referred microstructure variability means inconsistency. As the stabilization unfolds, a negative feedback mechanism function to form the macrostructure making interaction between the components well established. Since the components maintain their individuality within the skill configuration, the microstructure remains variable. However, in this case this does not mean inconsistency, but redundancy or flexibility (Corrêa et al., 2015; Tani et al., 
2014). Therefore, based on the results this state of organization was not achieved.

It is also interesting to note that groups that had the combination of practice schedules (constant-random and random-constant) showed a tendency to diminish the consistency of both macro- and microstructures in terms of spatial dimension (Figure 4). Maybe, for these groups the shift in the practice conditions, at a time when they were still seeking to establish a pattern of interaction between the motor skill components (backswing and forward swing), in itself generated perturbation. In this case, it could be thought they were not prepared for changing the practice schedule (De Paula Pinheiro et al., 2015). On the other hand, there may have been effects of the practice schedule specificity on the temporal and spatial dimensions of skill (Barros et al., 2017).

\section{Conclusions}

In summary, it can be concluded that constant, random and random-constant practices made possible the partial formation of the macro and microstructures, since their changes throughout the practice were associated with the improvement of the performance. The conclusion of only partial formation being achieved is because it was not robust enough to account for the perturbation and because the variability of the macrostructure was greater than the variability of the microstructure. This conclusion provides support for the assumption that functional stabilization is a prerequisite for adaptation (Tani et al., 2014). This conclusion inspire useful insights into the design of practice tasks by considering teachers and coaches should promote the practice of the golf putting not only to the moment that the goal was consistently achieved, but also that the movement pattern itself was consistent."

From these findings, we ask: (i) would the expected robustness in functional stabilization be achieved if golf putting practice was extended? (ii) Since macrostructure is constrained by intention, should preparation time be considered as a component of the task? These questions should be the focus in further studies. In addition, two other aspects deserve to be investigated in future studies: first is the fact of the club displacement has been recorded at a low acquisition rate. Maybe, a higher frequency of image capture could enable others important details of performance; second, since motor skills involve the interaction of force, space and time, others kinematic and/or kinetic measures resulting from this interaction could be used for an analysis of the hierarchical organization.

\section{REFERENCES}

Barros, J. A. C., Tani, G. \& Corrêa, U. C. (2017). Effects of practice schedule and task specificity on the adaptive process of motor learning. Human Movement Science, 55, 196-210. doi: 10.1016/j.humov.2017.07.011. 
Benda, R. N., Corrêa, U. C., Ugrinowitsch, H., Ambrósio, N. F. A., Tani, G. (2016). Variabilidade e processo adaptativo em aprendizagem motora. In G. Tani (Org.), Comportamento Motor: conceitos, estudos e aplicações (pp. 33-39). Rio de Janeiro: Guanabara Koogan.

Benda, R. N., Palhares, L. R., Vieira, M. M., Albuquerque, M. R., Januário, M. S., \& Ugrinowitsch, H. (2010). Is variability of response after and before stabilization of distinct nature? International Journal of Sport Psychology, (Special Issue) (Proceedings from the 2nd International Congress of Complex Systems in Sport and 10th European Workshop on Ecological Psychology), 47-48.

Chauvel, G., Maquestiaux F., Hartley A.A., Joubert S., Didierjean A., \& Masters R.S. (2012). Age effects shrink when motor learning is predominantly supported by nondeclarative, automatic memory processes: evidence from golf putting. Quarterly Journal of Experimental Psychology, 65, 25-38. DOI: 10.1080/17470218.2011.588714. Epub 2011 Jul 7.

Choshi, K. (1985). Adaptive process of perceptual-motor learning: complexity and complementarity. In Memoirs of the Faculty of Integrated Arts and Sciences VI (v. 3, pp. 21-30). Hiroshima: Hiroshima University Press. (in Japanese).

Choshi, K., \& Tani, G. (1983). Stable system and adaptive system in motor learning. In: Japanese Association of Biomechanics (Ed.) The science of movement (v. 5, pp.346-351). Tokio: Kiorin. (in Japanese).

Corrêa, U. C., Benda, R. N., Meira, C. M., Jr., \& Tani, G. (2003). Practice schedule and adaptive process in the acquisition of a manual force control task. Journal of Human Movement Studies, 44, 121-138.

Corrêa, U. C., Massigli, M., Barros, J. A. C., Gonçalves, L. A., Oliveira, J. A., \& Tani, G. (2010b). Constant-random practice and the adaptive process in motor learning with varying amounts of constant practice. Perceptual and Motor Skills, 110, 442-452. doi: 10.2466/pms.110.2.442-452

Corrêa, U. C., Ugrinowitsch, H., Benda, R. N., \& Tani, G. (2010a). Effects of practice schedule on the adaptive process of motor learning. Portuguese Journal of Sport Sciences, 10, 158-171.

Corrêa, U. C., Walter, C., Torriani-Pasin, C., Barros, J. A. C., \& Tani, G. (2014). Effects of the amount and schedule of varied practice after constant practice on the adaptive process of motor learning. Motricidade Journal, 10, 33-46.

Corrêa, U. C., Benda, R. N., Oliveira, D. L., Ugrinowitsch, H., Freudenheim, A. M. \& Tani, G. (2015). Different faces of variability in the adaptive process of motor skill learning. Nonlinear Dynamics, Psychology and Life Sciences, 19, 465-487.

Corrêa, U. C., Correia, W. R., \& Tani, G. (2016). Towards the teaching of motor skills as a system of growing complexity. In: M. Koopmans \& D. Stamovlasis. 
(Orgs.). Complex Dynamical Systems in Education: Concepts, Methods and Applications (pp. 93-103). New York: Springer. https://doi.org/10.1007/978-3-319-27577-2_6

Corrêa, U. C., Massigli, M., Barros, J. A. C., Gonçalves, L. A., Tani, G. \& Oliveira, J. A. (2010). Constant-random practice and the adaptive process in motor learning with varying amounts of constant practice. Perceptual and Motor Skills, 110, 442-452. doi: 10.2466/PMS.110.2.442-452

De Paula Pinheiro, J., Marques, P. G., Tani, G. \& Corrêa, U. C. (2015). Diversification of motor skills rely upon an optimal amount of variability of perceptive and motor task demands. Adaptive Behavior, 23, 83-96, 2015. https://doi.org/10.1177/1059712315571369

Everitt, B. S., Landau, S. \& Leese, M. (2001). Cluster Analysis. London: Edward Arnold.

Ford, D. H., \& Lerner, R. M. (1992). Developmental systems theory: An integrative approach. Newbury Park, CA: Sage.

Kauffman, S. A. (1995). At home in the universe: the search for laws of complexity. London: Penguin Books.

Kaufman, L. \& Rousseeuw, P. J. (1990). Finding Groups in Data. New York: John Wiley \& Sons.

Kelso, S. J. A. \& Engostrom, D. A. (2006). The complementary nature. London, MIT Press.

Laszlo, E. (2002). The systems view of the word: a holistic vision for our time. Cresskill, NJ: Hampton Press, Inc.

Lewin, R. (1999). Complexity: Life on the edge of chaos. London: The University of Chicago Press.

Nunes, M. E. S., Souza, M. G. T. X., Basso, L., Coelho, D. B., Corrêa, U. C., \& Santos, S. (2018). Self-controlled knowledge of performance does not improve the learning of golf putting by older persons. Journal of Aging and Physical Activity, 30, 1-28. doi: 10.1123/japa.2018-0053

Oliveira, T. A. C., Denardi, R. A., Tani, G., \& Corrêa, U. C. (2013). Effects of internal and external attentional foci on motor skill learning: testing the automation hypothesis. Human Movement, 14, 194-199. doi: 10.2478/humo2013-0022

Poolton, J. M., Maxwell, J. P., Masters, R. S. W., \& Raab, M. (2006). Benefits of an external focus of attention: Common coding or conscious processing? Journal of Sport Sciences, 24, 88-99. doi: 10.1080/02640410500130854.

Salthe, S. N. (2012). Hierarchical structures. Axiomathes, 22, 355-383. doi: 10.1007/s10516-012-9185-0

Schmidt, R. A. (1982). The schema concept. In J.A.S. Kelso (Ed.), Human motor behavior: a introduction (pp.219-235). Hillsdale: Lawrence Erlbaum. 
Tani, G. (1995). Hierarchical organization of an action programme and the development of skilled actions. Unpublished Technical Report. Sheffield, UK: University of Sheffield, Department of Psychology.

Tani, G. (2005). Programação motora: organização hierárquica, ordem e desordem. In G. Tani (Ed.), Comportamento motor: aprendizagem $e$ desenvolvimento (pp.82-105). Rio de Janeiro: Guanabara Koogan.

Tani, G., Corrêa, U. C., Basso, L., Benda, R. N., Ugrinowitsch, H., \& Choshi, K. (2014). An adaptive process model of motor learning: Insights for the teaching of motor skills. Nonlinear Dynamics, Psychology, and Life Sciences, 18, 47-65.

von Bertalanffy, L. (1952). Problems of life. London: Watts.

Weiss, P. A. (1971). The basic concept of hierarchic systems. In P. A. Weiss, P.A. (Ed.), Hierarchically organized systems in theory and practice (pp.1-44). New York: Hafner. 